\title{
THE RELATIONSHIP BETWEEN THE PERCEIVED \\ PSYCHOLOGICAL RESILIENCE AND SOCIAL SUPPORT IN \\ CAREGIVERS OF PATIENTS WITH SCHIZOPHRENIA
}

Neslihan LÖK ${ }^{1}$, Kerime BADEMLI ${ }^{2}$

${ }^{1}$ Selcuk University, Faculty of Nursing, Psychiatric Nursing Department Konya, Turkey

Akdeniz University, Faculty of Nursing, Psychiatric Nursing Department, Antalya, Turkey

\section{Objectives}

The objective of this study was answer to the question: to what extent are the psychological resilience of the caregivers of patients with schizophrenia and their perceived level of social support are related?

\section{Background}

Due to the difficulties experienced by caregivers in the process of providing care to patients with schizophrenia, they are more likely to have social isolation. Caregivers may often feel themselves isolated from their families and friends in maintaining the care of their patients.

\section{Methods}

The population of the study consists of primary caregivers of schizophrenia patients at the age of 18 and above registered at the Community Mental Health Center. The researchers created an information form to collect the participants' socio-demographic data. The researchers also used the Resilience Scale for Adults and the Multidimensional Scale of Perceived Social Support. Mann-Whitney U test, Anova, t-test and correlation analysis were also used.

\section{Results}

The psychological resilience of the caregivers according to the score averages was determined as $88.15 \pm 11.62$, and the total perceived social support score was determined as $41.89 \pm 5.27$. When the relationship between psychological resilience total score and perceived social support total score evaluated, it was determined that there was a positive and high relationship between psychological resilience total point average and perceived social support total point average.

\section{Conclusions}

According to the results obtained from this study, regarding the importance of resilience and perceived social support to the caregiver and the resultant effect on resilience and perceived social support gives the nurse evidence-based knowledge to apply to the caregiver.

\section{REFERENCES}

Dyer, J. G., \& McGuinness, T. M. (1996). Resilience: Analysis of the concept. Archives of Psychiatric Nursing, 10(5), $276-282$.

Gater, A., Rofail, D., Tolley, C., Marshall, C., Abetz-Webb, L., Zarit, S. H., \& Berardo, C. G. (2014). "Sometimes it's difficult to have a normal life": Results from a qualitative study exploring caregiver burden in schizophrenia. Schizophrenia Research and Treatment, 368215:1-13

Kate, N., Grover, S., Kulhara, P., \& Nehra, R. (2013). Relationship of caregiver burden with coping strategies, social support, psychological morbidity, and quality of life in the caregivers of schizophrenia. Asian Journal of Psychiatry, 6(5), 380-388.

Ribé, J. M., Salamero, M., Pérez-Testor, C., Mercadal, J., Aguilera, C., \& Cleris, M. (2018). Quality of life in family caregivers of schizophrenia patients in Spain: caregiver characteristics, caregiving burden, family functioning, and social and professional support. International Journal of Psychiatry in Clinical Practice, 22(1), 25-33. 